\title{
Numerical Study of the Influence of Flow Control to the Kinetic Detachment in the Near-Wake of an Ahmed Body
}

\author{
M. Tientcheu-Nsiewe, D. Tcheukam-Toko, M. Edoun, M. Tchawe-Tchawe, R. Wafo, and T. Djiako
}

\begin{abstract}
Environmental pollution represents today the greatest danger to which the world has to do faces. Several activities of human are accused. Among the more devastative, the transport sector and in particular that of the car remains more to be feared. For control and to reduce the impact of the pollution of this sector on the environment, it is necessary to control the profile of the flow around the vehicle. The structure of the flow around a motor vehicle is strongly separated and swirling. It presents recirculation's zones of upstream and downstream from this one. For thus modeling these various swirling structures, we carried out a study on three configurations of vehicle. The purpose of this numerical study is to arise the turbulent character of the flow in the near wake of the Ahmed body. The к- $\varepsilon$ turbulent model has been applied. This simulation is based on the Navier-Stokes equations. The results which we obtain make it possible to see that the size of the zone of wake is a function of the extent of separation, of the slack angle, of the rear window and upstream speed. Comparison of numerical results with the experimental plot available in the literature is satisfactory.
\end{abstract}

Keywords - Ahmed Body, CFD, Near-Wake, Flow Control, Kinetic Detachment.

\section{INTRODUCTION}

In the last century, the development of the chemical and petroleum industries has led to a proliferation and diversification of air pollutants. In Europe, the transport sector contributes at $26 \%$ in the air pollution according to ACEA. Moreover, the transport sector depends on the petroleum for more than $95 \%$ of its energy needs. In Africa, according to [1], the sector of road transport cover goods traffic for approximately $80 \%$ and traffic passengers for $90 \%$. Automobile pollution can generate in certain countries of Africa of enormous cost, nearly $2 \%$ of the GDP. Research in the field relates to mainly the improvement of the flow around the vehicle (aerodynamic).

The flow around a real motor vehicle is very complex,

Submitted on December 03, 2021

Published on January 08, 2022.

M. Tientcheu-Nsiewe, Science and Technical Department, National Advance School of Chemistry Engineering and Mineral Industries, Ngaoundere State University, Cameroon.

(e-mail: maxwelltientcheunsiewe@ gmail.com)

D. Tcheukam-Toko, Mechanical Engineering Department, College of technology, Buea State University, Cameroon.

(e-mail: tcheukam_toko@yahoo.fr)

M. Edoun, deputy director, University Institut of Tchnology, Ngaoundere State University, Cameroon.

(e-mail: m_edoun@yahoo.fr) sometimes detached and often strongly three-dimensional. Author [2] defines three types of simplified vehicle geometry: the "squareback" vehicle, the "fastback" vehicle, and the "notchback" vehicle. Previous experimental studies of [3], [4] and [5], make it possible to identify the flow topology that develops around this geometry. This topology is successively presented on the front and back part of the geometry. Results indicated that almost $85 \%$ of total aerodynamic resistance is contributed by pressure drag and most of this drag is generated at the rear end. The impact of the aerodynamic drags on the power consumption, and consequently on the emissions of $\mathrm{CO}_{2}$ and gas for purpose of greenhouse, is then considerable.

Three types of flow were identified by [2], [3], this function to the slack angle $\alpha$ of the rear window. Below the least critical slack angle $\left(\alpha_{\mathrm{m}}<12^{\circ}\right)$, we note that the flow remains dependent on the surface of the rear window before takes off near to the periphery of the base: The flow is known as of right base; For a slack angle ranging between $12<\alpha<$ 30 , the flow which was firstly two-dimensional on the top of the cross section of the body becomes three-dimensional. Higher vortex tendency has to be placed on point of detachment. For a slack angle $\alpha>30$, the two vortices are completely stuck on the slack angle and the right base. The two areas of recirculation are strongly influence by the separation of glasses. The flow return has that of right base type. Other authors [4] note that, a detachment generally appears to $8 \%$ of the length $\mathrm{L}$ of Ahmed body. According to [4] [5], these vortical structures are advected along the pavilion to wake zone. The complexity of the flow then holds the coexistence of transverse vortices on the rear window and at the bottom, and longitudinal vortices which develop on the side edges of the rear window. [6]-[10], let show that, the upstream flow and the wake structure have a major responsibility in determining for drag model. This is based on determining of the equations drag and the turbulence model used. The method of finite volumes is used like principal method of discretization of the Navier-Stokes equations in more numerical simulation. The model more used has two equations.

The more share of author is focused on the flow control

M. Tchawe-Tchawe, Mechanical Engineering Department, National Advance School of Agro-Industrial Sciences, Ngaoundere State University, Cameroon.

(e-mail: christophetchawe@ ${ }^{@}$ ahoo.fr)

R. Wafo, PhD student in Applied Physics and Engineering, National Advanced School of Agro-Industrial Sciences, Ngaoundere State University, Cameroon.

(e-mail: waforaoul7@gmail.com)

T. Djiako, Thermal and Renewable Energy Department, Institut Universitaire du Golfe de Guinée, Cameroon.

(e-mail: thomasdjiako@yahoo.fr) 
separation on the rear window [11]-[14]. These authors propose at the same time numerical and experimental data base on control of the flow in the near wake of Ahmed body. We have two types of control: active control and passive control. Research is directed towards control by continuous blowing or aspiration of air. More particularly in upstream of the separation line, on the rear window (separated zone) and in the wake.

To the end of this review, we realize that more authors' studies are focused on the analysis of the flow detachment around the Ahmed body. While other authors are interested in control of the flow. More the share of the authors neglects the fact that in reality, the flow strongly turbulent and diversified. This present work consists in doing a numerical study of the influence of flow control to a kinetic detachment of a turbulent flow in the near-wake of an Ahmed Body.

This work allows us to understand not only the flow around an automobile vehicle, but also to control this one in order to have maximum reductions of drag. It will also enable us to know the influence of the upstream speed and the base speed on the flow in near wake of Ahmed body. Our work will be articulated around three principal parts. First of all, we will present the mathematical equations allowing us to model the flow around Ahmed body. Then we present the various geometries used for the numerical simulation (with control and without control). We will finish by the presentation of the results obtained on form of profile.

\section{RESEARCH METHOD}

\section{A. Physical Model}

We have two types of simulation. Firstly, we simulate the geometry proposed by [11]. The geometry simulate in the air is the Ahmed body (scale 1/50). The lower part is base and is positioned at a height $\mathrm{h}=4 \mathrm{~mm}$ from the digital wind tunnel floor. The length $\mathrm{L}$ and the height $\mathrm{H}$ of the geometry are $80 \mathrm{~mm}$ and $22 \mathrm{~mm}$ respectively. We have three configurations of simplified model of Ahmed body on which we will simulate flow showing in table 1 below.

\begin{tabular}{cc}
\multicolumn{2}{l}{ TABLE I: SLACK ANGLE PROPOSED BY [11] } \\
\hline 1st case & $\alpha<\alpha_{\mathrm{m}}, 5^{\circ}$ \\
2nd case & $\alpha_{\mathrm{m}}<\alpha_{\mathrm{m}}<\alpha_{\mathrm{M}}, 25^{\circ}$ \\
3th case & $\alpha_{\mathrm{M}}<\alpha, 40^{\circ}$ \\
\hline
\end{tabular}

These angles in above table represent the various flow structures defined by [11]. The representation of geometry simulate (Ahmed body) is shown in Fig. 1. On the figure below, we see the different values of various angles and their size. These different cases represent the various structures of the flow around the Ahmed body like define by [2]. The device is thus placed in a numerical blower. The various sizes and dimensions are also represented on the figure. The reference axis ( $\mathrm{X}$ and $\mathrm{Y}$ ) is linked to the Ahmed body. The numerical win tunnel in which the Ahmed body is placed is rectangular and their dimension (height (H1) and the length (L1)) respect the assumption of [15]: $10 \mathrm{H}$ on the height and $30 \mathrm{~L}$ on the length. This assumption on dimensions makes it possible to be freed during the flow of the possible interactions between the conditions imposed on the limits of the field of simulation and the flow in the proximity of the Ahmed body. The uniform pressure in the outlet area is $\mathrm{P}_{0}=101325 \mathrm{~Pa}$.

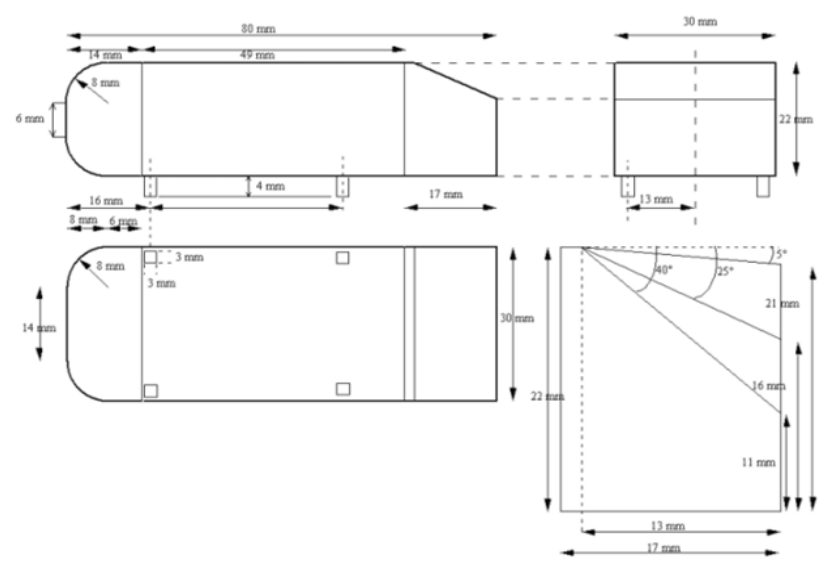

Fig. 1. Ahmed geometric used.

The second geometry is presented in Fig. 2. The control improves the performances of the flow over the car. In this configuration, the flow which interests us is the downstream flow. The blower is brought back to the level of the back base. The base of the geometry receives an imposed speed and is used like control field of flow. V1 speed imposed in the base is lower than $\mathrm{V}_{0}$ speed of reference to model the deficit speed in the base associated with the side escapes [3]. Five cases study are considered:

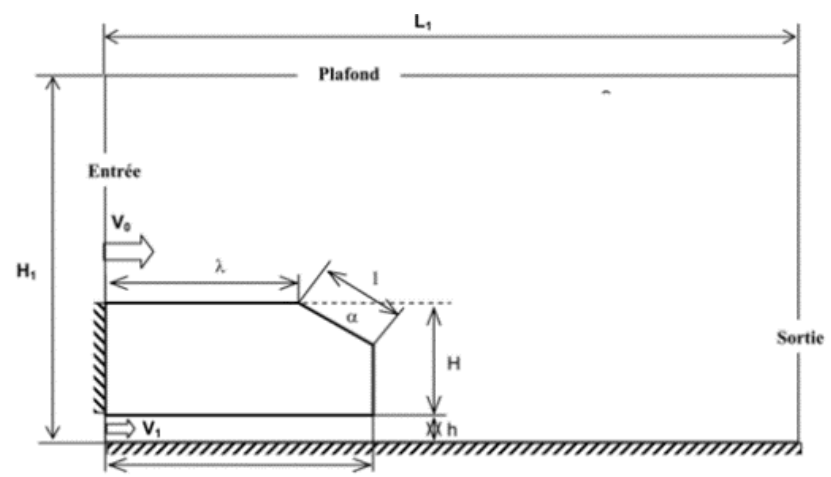

Fig. 2. Ahmed geometric used [13].

The flow is advected from the left to the right and the fluid is initialized to the speed $\mathrm{V}_{0}$. The Reynolds number associated is of $\operatorname{Re}=6 \times 10^{6}$. The slack angle of the rear window $\alpha$ is 25 . Dimensions of the blower are defined by [15]. The same condition of previously study is applied.

\begin{tabular}{cccc}
\multicolumn{4}{c}{ TABLE II: DIFFERENT CASES STUDY } \\
\hline Case & $\mathrm{V} 1$ & $\mathrm{~V} 0$ & model \\
\hline Case 1 & $40 \mathrm{~m} \cdot \mathrm{s}^{-1}$ & $40 \mathrm{~m} \cdot \mathrm{s}^{-1}$ & $\mathrm{~V}_{1}=\mathrm{V}_{0}$ \\
Case 2 & $25 \mathrm{~m} \cdot \mathrm{s}^{-1}$ & $25 \mathrm{~m} \cdot \mathrm{s}^{-1}$ & $\mathrm{~V}_{1}=\mathrm{V}_{0}$ \\
Case 3 & $12.5 \mathrm{~m} \cdot \mathrm{s}^{-1}$ & $12.5 \mathrm{~m} \cdot \mathrm{s}^{-1}$ & $\mathrm{~V}_{1}=\mathrm{V}_{0}$ \\
Case 4 & $4 \mathrm{~m} \cdot \mathrm{s}^{-1}$ & $4 \mathrm{~m} \cdot \mathrm{s}^{-1}$ & $\mathrm{~V}_{1}=\mathrm{V}_{0}$ \\
Case 5 & $25 \mathrm{~m} \cdot \mathrm{s}^{-1}$ & $40 \mathrm{~m} \cdot \mathrm{s}^{-1}$ & $\mathrm{~V}_{1}=0,6 \mathrm{~V}_{0}$ \\
\hline
\end{tabular}

Source: [14].

\section{B. Governing Equations}

The Reynolds Averaged Navier-Stokes (RANS) equations solved by fluent are presented there. The RANS equations approach permitted to solve for the mean flow variables reduces the computational effort. After average and 
simplifies by various methods, we obtain the following equations:

$$
\begin{aligned}
& \frac{\partial \rho}{\partial t}+\frac{\partial\left(\rho u_{i}\right)}{\partial x_{i}}=0 \\
& \frac{\partial\left(\rho u_{i}\right)}{\partial t}+\frac{\partial\left(\rho u_{i} u_{j}\right)}{\partial x_{j}}=\frac{\partial p}{\partial x_{i}}+A+B
\end{aligned}
$$

Here,

$A=\frac{\partial\left(\mu\left(\frac{\partial u_{i}}{\partial x_{j}}+\frac{\partial u_{j}}{\partial x_{i}}-\frac{\partial \delta_{i j} \partial u_{i}}{3 \partial x_{i}}\right)\right)}{\partial x_{j}}$

and

$$
B=\frac{\partial\left(-\overline{\rho u_{\imath}^{\prime} u_{\jmath}^{\prime}}\right)}{\partial x_{j}}
$$

This approach is generally adopted for all practical engineering calculations, and is used with turbulence models Realizable k- $\mathcal{E}$ Turbulence Model:

$\frac{\partial(\rho \varepsilon)}{\partial t}+\frac{\partial\left(\rho k u_{j}\right)}{\partial x_{j}}=\frac{\left.\partial\left(\left(\mu+\frac{u_{t}}{\sigma_{k}}\right) \frac{\partial k}{\partial x_{j}}\right)\right)}{\partial x_{j}}+G_{k}+G_{b}-\rho \varepsilon-Y_{M}+S_{k}$

$$
\begin{aligned}
& \frac{\partial(\rho \varepsilon)}{\partial t}+\frac{\partial\left(\rho \varepsilon u_{j}\right)}{\partial x_{j}}=\frac{\left.\partial\left(\left(\mu+\frac{u t}{\sigma_{\varepsilon}}\right) \frac{\partial \varepsilon}{\partial x_{j}}\right)\right)}{\partial x_{j}}+\rho C_{1} S \varepsilon-\rho C_{2} \frac{\varepsilon^{2}}{k+\sqrt{v \varepsilon}}+ \\
& C_{1 \varepsilon} \frac{\varepsilon}{k} C_{3 \varepsilon} G_{b}+S_{\varepsilon}
\end{aligned}
$$
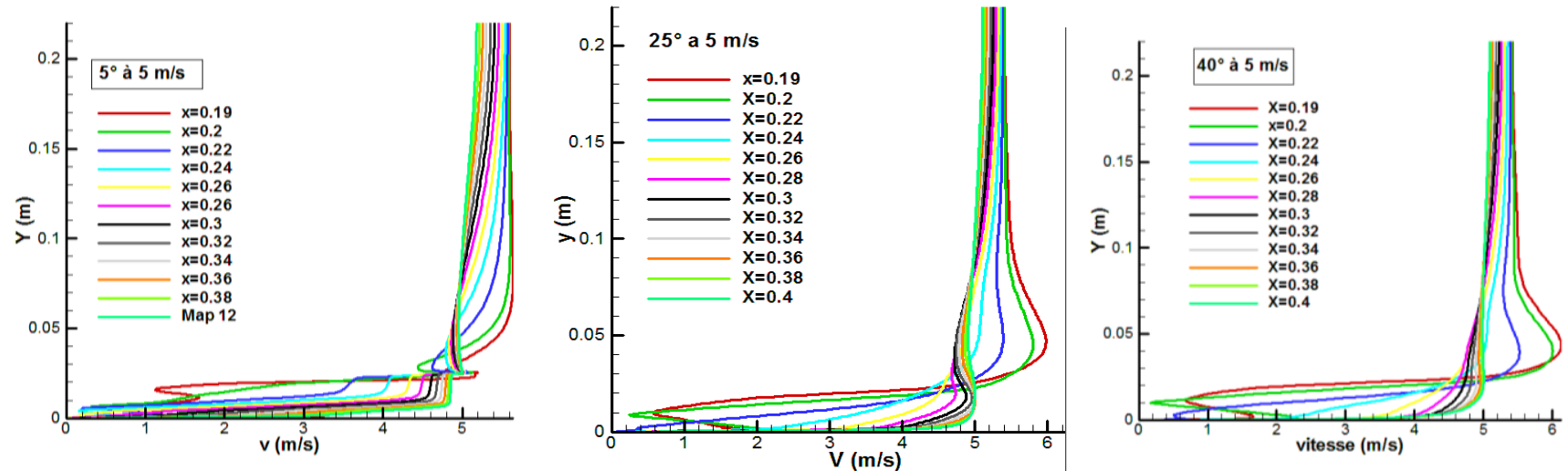

Fig. 3. Velocity field for various slack angles for $V_{0}=5 \mathrm{~m} / \mathrm{s}$.
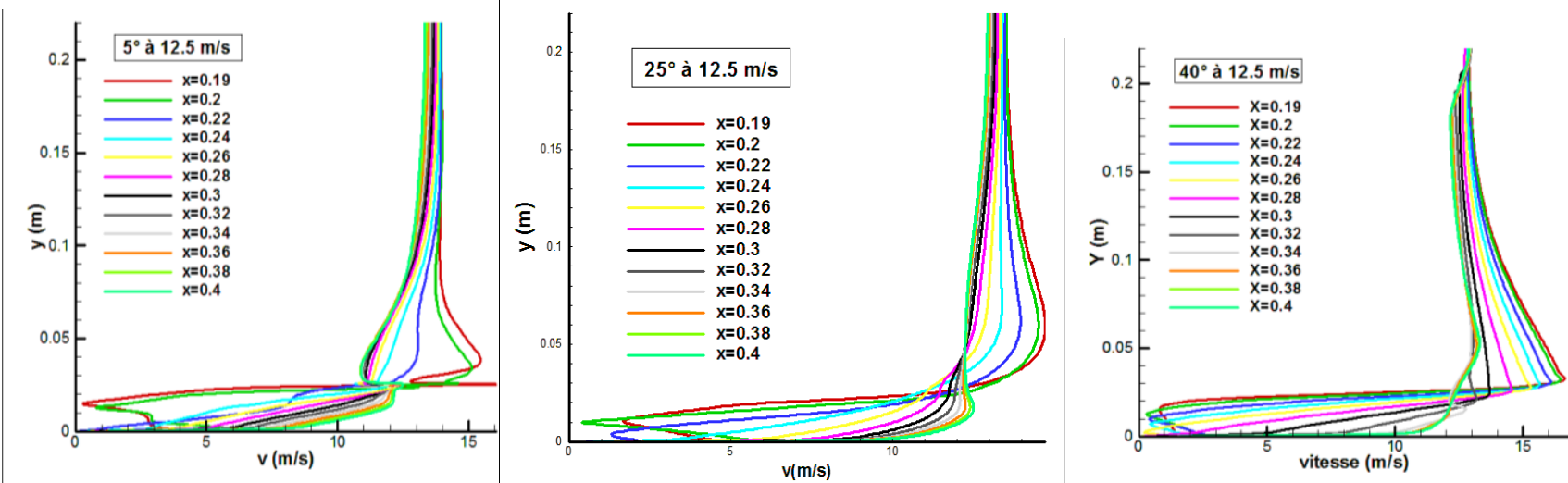

Fig. 4. Velocity field for various slack angles for $\mathrm{V}_{0}=12.5 \mathrm{~m} / \mathrm{s}$. 

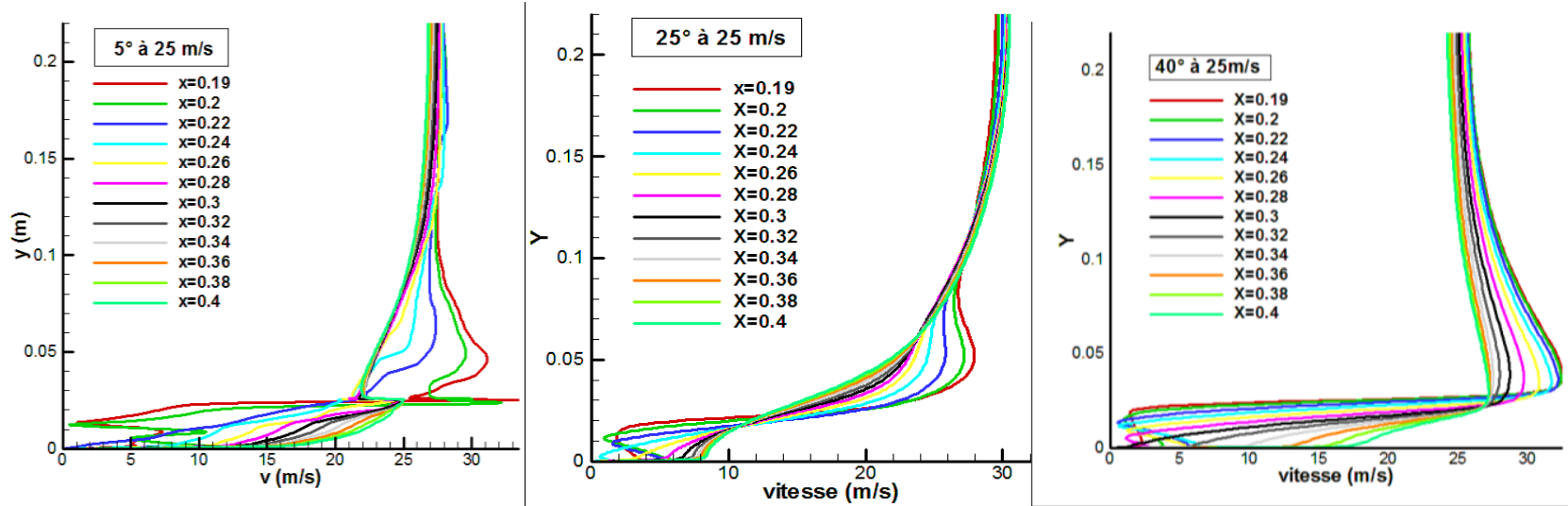

Fig. 5. Velocity field for various slack angles for $V_{0}=25 \mathrm{~m} / \mathrm{s}$.
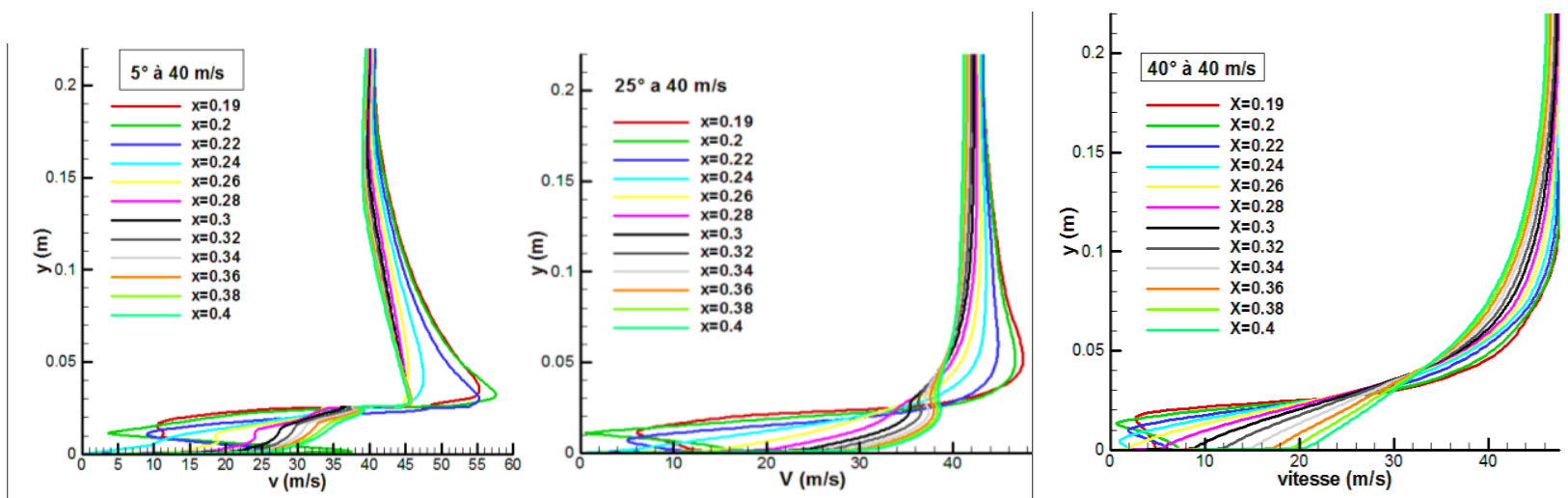

Fig. 6. Velocity field for various slack angles for $V_{0}=40 \mathrm{~m} / \mathrm{s}$.
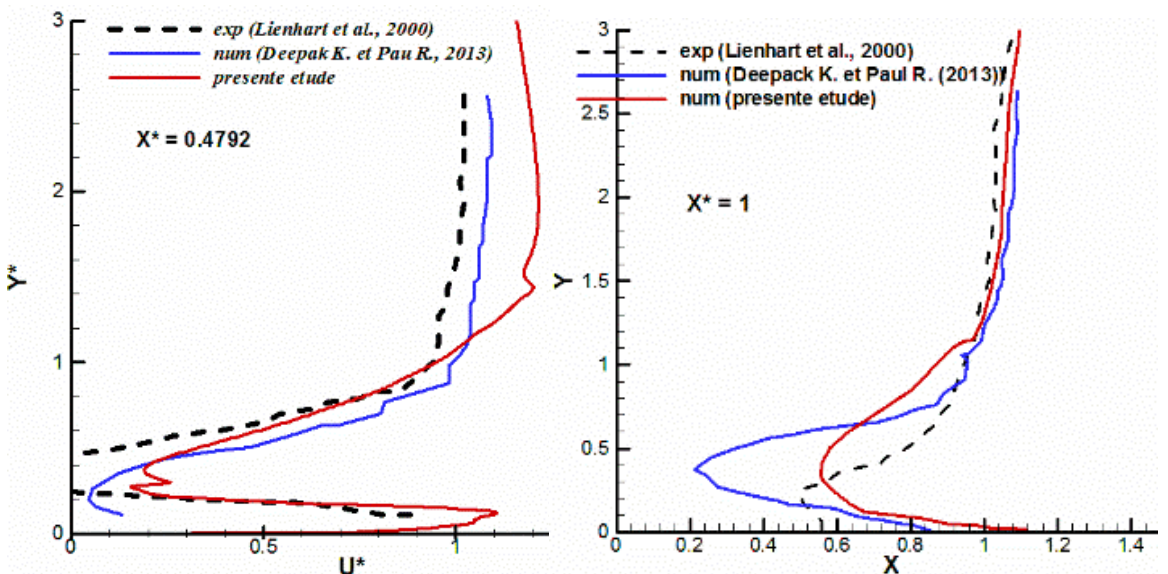

Fig. 7. Velocities fields compare to another authors.

We observe for different slack angles, the backflow area at the upstream of flow described by [2]. The speed of these areas varied from $1.5 \mathrm{U}_{\infty}$ to $2 \mathrm{U}_{\infty}$. Far from the body, the speed profile is characterized by a negative velocity vector zone then positive, before increasing abruptly until reaching speeds higher than $\mathrm{U} \infty$. Thereafter it evolves linearly towards the inlet velocity of the fluid into the input fan. These different changes indicate the presence of a dynamic boundary layer between the wake and the flow area far from the wall. This decrease in speed in the near wake zone characterizes the contra-rotating vortices that are developed in this part of the enclosure. The boundary layer becomes turbulent at high speed, which is why the profile is very low at the edge. The speed profiles near of the edge are representative of the laminar boundary layers.

However, the flow inside the boundary layer rest laminar to a certain place of the edge before becoming turbulent.
Inside the turbulent boundary layer, there is a very thin, nearly laminar flow layer, which is called a laminar boundary layer or a laminar film. The distance between the edge and transition point where the boundary layer stay turbulent is called the critical length [18].

Once the speed profiles have been drawn, it would be important to compare them with the experimental ones. The visualization of the experimental results is generally done in 3D (three-dimensional according to the techniques of measurements to use) but the presentation here is in 2D so the parietal effects can play on the high quality of the results (Fig. 4). Velocity profile for Ahmed Body slack angle a) $\alpha=5^{\circ}$, b) $\left.\alpha=5^{\circ}, \mathrm{c}\right) \alpha=5^{\circ}$.

Our results describe more precisely the detachment phenomenon and the exit of boundary layer. Indeed, in the figure presented above, the experimental profile obtained by [5] does not show the characteristics of the near wake area at 
$\mathrm{x} *=0.479$ between $0.5<\mathrm{y} *>0.6$. The profile seems to get lost in this area which actually represents the line of division between two rotating Centro vortices identified by [4]. While our study clearly shows the variation of the speed in this important interval for the definition of the boundary layer and the detachment bulb. [10], although having managed to release the speed profile in this interval, could not get the profile out in the thin boundary layer in underflow. What our study can describe. This shows indeed a significant advance of our study compared to those of [5] [10].

The same think is observed for the speed profile at $\mathrm{X} *=$ 1. The profile we present can describe with that of [10] the outflow from the bedrock, but our own is getting closer more experimental results than those of these authors. These results highlight the difficulty of experimentally describing the bedrock flow process, which is an important factor in the determination of the wake zone of the detachment observed in that.

\section{B. Velocities with Control}

Here we present the velocity profiles in the zone of recirculation to determine the nature of the boundary layer that develops there, and also to be able to visualize with more precision the nature of the vortices which appears there.
The profile obtained has the same pace as the speed profile obtained without bedrock control. Indeed, the speed profile is also characterized by a vector velocity zone that alternately changes positively and negatively, before increasing abruptly until velocities greater than $U \infty$ is reached. Thereafter it evolves linearly towards the speed of input of the fluid into the vein. These various changes show, as previously described the presence of a dynamic boundary layer between the wake zone and the flow away from the wall. This decrease in speed in the near wake zone, still characterizes contrarotating vortices that are developed in this part of the enclosure.

The velocity profiles near the edge are representative of the laminar boundary layers. Taking the consideration of the underfloor flow is observed on the nature of the profile in the laminar boundary sublayer, which becomes substantially linear, at the exit of the laminar boundary layer which is linearly also. The laminar film has totally disappeared. The flow inside the boundary layer remains laminar over its entire surface. This result sufficiently shows the role of taking the consideration of the underfloor flow in the reduction of the aerodynamic drag force.

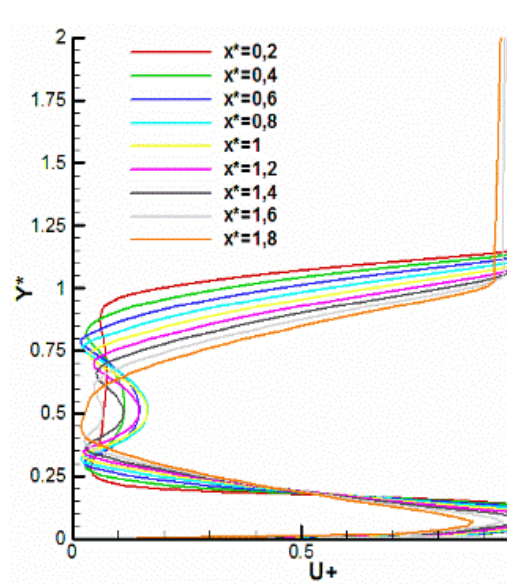

Fig. 8. Velocity fields for Ahmed Body in different positions for $\mathrm{U}_{0}=\mathrm{U}_{1}=40 \mathrm{~m} / \mathrm{s}$.

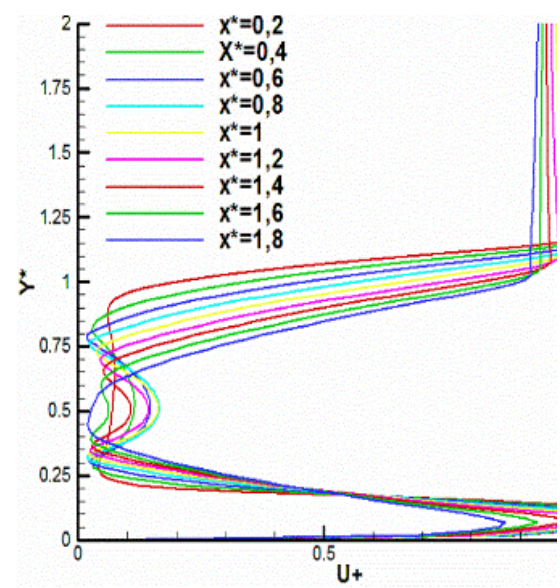

Fig. 9. Velocity fields for Ahmed Body in different positions for $\mathrm{U}_{0}=\mathrm{U}_{1}=25 \mathrm{~m} / \mathrm{s}$.

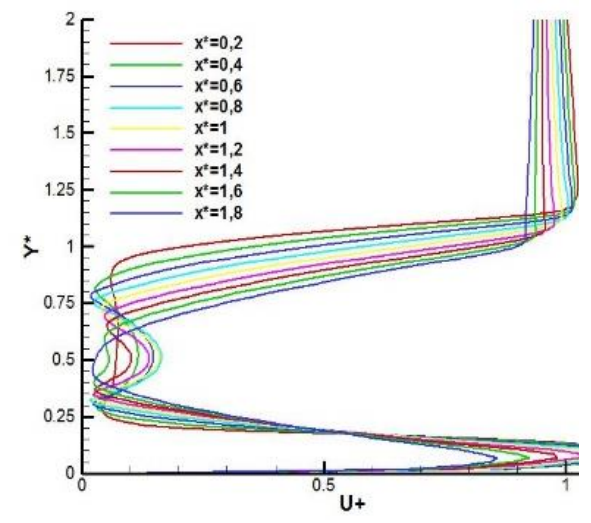

Fig. 10. Velocity fields for Ahmed Body in different positions for $\mathrm{U}_{0}=\mathrm{U}_{1}=12.5 \mathrm{~m} / \mathrm{s}$.

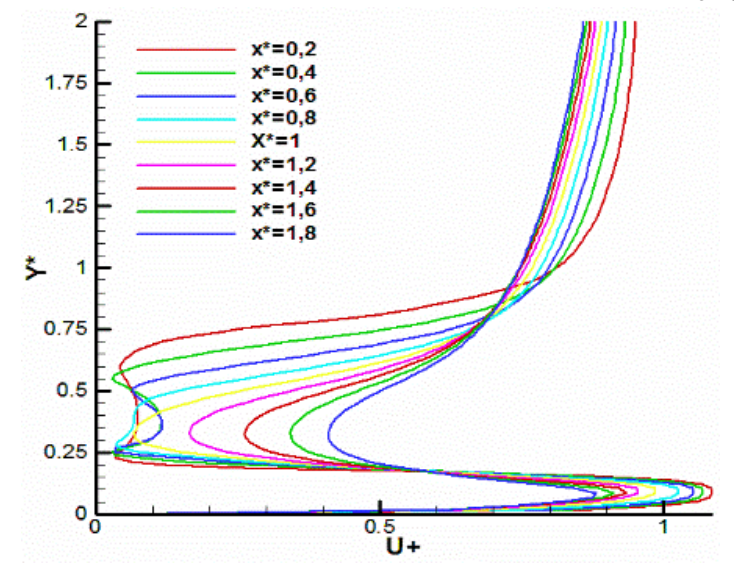

Fig. 11. Velocity fields for Ahmed Body in different positions for $\mathrm{U}_{0}=\mathrm{U}_{1}=4 \mathrm{~m} / \mathrm{s}$.

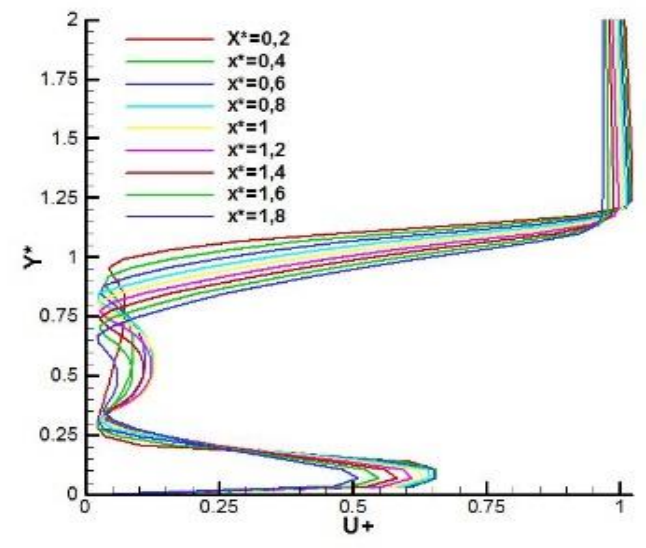

Fig. 12. Velocity fields for Ahmed Body in different positions for $\mathrm{U}_{0}=40$ and $\mathrm{U}_{1}=25 \mathrm{~m} / \mathrm{s}$. 


\section{CONCLUSION}

In the end of this wok, we note that the limit of these results coming from the imprecise nature of the bedrock flow allows us to introduce speed control of this one following the numerical device of [11] under five (5) studies $\left(\mathrm{V}_{1}=\mathrm{V}_{0}=\right.$ $40 \mathrm{~ms}^{-1}, \mathrm{~V}_{1}=\mathrm{V}_{0}=25 \mathrm{~ms}^{-1}, \mathrm{~V}_{1}=\mathrm{V}_{0}=12.5 \mathrm{~ms}^{-1}, \mathrm{~V}_{1}=\mathrm{V}_{0}=$ $4 \mathrm{~ms}^{-1}$ and for $\mathrm{V}_{1}=40 \mathrm{~m} / \mathrm{s}$ and $\mathrm{V}_{0}=40 \mathrm{~ms}^{-1}$ ). We find the same results as Ahmed et al., (1984) regarding the closure flow on the right pellet, the torus-shaped recirculation zone upstream and the volume of the unglued zone. which always varies function of the speed of the flow. For speeds of $25 \mathrm{~m} /$ $\mathrm{s}$ and more, the detachment bulb is drowned in the upstream speed and therefore modifies only very little the flow at the end of the flag unlike at low velocity or the detachment bulb appears [4]. Given that the underbody control causes speed losses and that at the same speed in the basement the wake zone is mastering, how to master the detachment bulb that appears?

\section{REFERENCES}

[1] CEA-NU. report on African exam in transport, the transport sector in Africa: importance, evolution and born problems, Unite Nation Economic. Commission for Africa, 2009, P.98.

[2] Ahmed S., Ramm R. \& Falting G. Some salient features of the time averaged ground vehicle wake. SAE technical paper series 840300 1984. Detroit.

[3] Chometon F. \& Gilliéron P. modelization of tridimensional flow detachment around a automobile vehicle. Congres SIA, Automobile

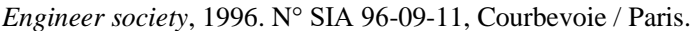

[4] Spohn A. \&Gilliéron P. Flow Separations Generated by a Simplified Geometry of an Automotive Vehicle, Congress IUTAM Symposium on Unsteady Separated Flows, 2002, April 8-12, Toulouse - France.

[5] Lienhart H., Stoots C. \& Becker S. Flow and turbulence structures in the wake of a simplified Car Model (Ahmed Model): roc. DGLR Fach. Symp. Der AG STAB. 2002 - Stuttgart Univ.

[6] Krajnovic S. \& Davidson L. "Contribution Large-Eddy Simulation of the Flow Around a Simplified Car Model", SAE International Congress \& Exposition. 2004. detroit, Michigan.

[7] Guilmineau E. Computational study of flow around a simplified car body, Journal of Wind Engineering and Industrial Aerodynamics. 2008; 96: 1207-1217.

[8] Chauhan B. \& Thundil R. Numerical Investigation of External Flow around the Ahmed Reference Body Using Computational Fluid Dynamics. Research Journal of Recent Sciences. 2012; 1(9): 1-5, September, ISSN 2277-2502.

[9] Alonso-Estébanez A., Pascual-Muñoz P., Yagüe C., Laina R. \& CastroFresno D. Field experimental study of traffic-induced turbulence on highways. Atmospheric Environment. 2012; 61: 189-196.

[10] Deepak K. \& Paul A. Computational Study of Flow around a Simplified 2D Ahmed Body. International Journal of Engineering Science and Innovative Technology (IJESIT). 2013; 2, Issue 3, ISSN 2319-5967.

[11] Roumeas M. Contribution to the analysis and control of thick body wakes by continuous suction and blowing, phd these, national polytechnic school of Toulouse. 2006, N2348, p. 235.

[12] Kourta A. \& Gilliéron P. Impact of the Automotive Aerodynamic Control on the Economic Issues, Journal of Applied Fluid Mechanics. 2009; 2: 69-75. No. 2, ISSN 1735-3645.

[13] Gosse K. experimental study of the dispersion of a passive scalar in the near wake of an Ahmed body, phd these. faculty of sciences university of Rouen. 2005; P. 177.

[14] Tientcheu-Nsiewe M., Tcheukam-Toko D., Murzyn F., Mehel A. \& Patte-Rouland B. Numerical Study of a Turbulent Flow in the NearWake of an Ahmed Body. American Journal of Environmental Engineering. 2016; 6(6): 157-163.

[15] Chen S. \& Doolen G. Lattice Boltzmann Method for fluid flows. Ann. Rev. Fluid Mech. 1998; 30: 329-354.

[16] Jones J. \& Lauder B. A Single Formula for the Law of the Wall. Journal of Applied Mechanics. 1961; 28: 444-458. No. 3.

[17] Patankar V. Numerical heat transfer and fluid flow, Mc Graw Hill. 1980.
[18] Tcheukam-Toko D., Kongue L., Koueni-Toko C., Mouangue R.\& Bélorgey M. Numerical Simulation and Experimental Validation of Boundary Layer Generated by a Turbulent Flow on a hydraulically Smooth Bed, Res. J. of Applied Sci. 2012; 7(2):108-112.

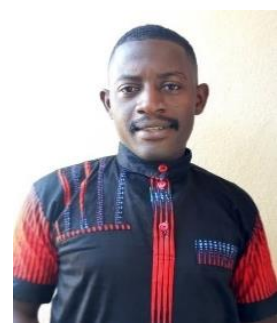

M. Tientcheu-Nsiewe, born in Banka, Ouest Region of Cameroon. He obtained Bachelor of Engineering in Thermal Engineering, University of Douala - littoral region, Cameroon, (2009), Master of Engineering in process and Thermal Engineering, Ngaoundere University, Adamawa region, Cameroon (2013), and $\mathrm{PhD}$ in same specialty at the same University (2019).

$\mathrm{He}$ is a lecturer in the Department of Science and Technical Engineering, National Advance School of Chemistry Engineering and Minerals Industries, Ngaoundere State University. His areas of specialization are fluids mechanics and thermal Engineering. Dr. Tientcheu-Nsiewe is a corporate member of Cameroonian Combustion Society.

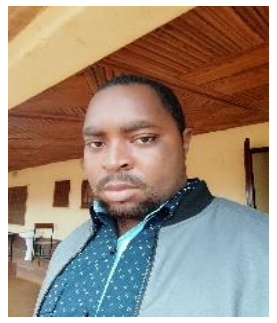

Wafo Raoul D. was born on 06th July 1985 at Bafoussam, Cameroon. He obtained Bachelor of Mechanical industrial and maintenance, University of Ngaoundere, Cameroon, (2013), Masters of Mechanical and Production Engineering, University of Ngaoundere, Cameroon, (2015), and $\mathrm{PhD}$ student in Mechanical Engineering, University of Ngaoundere, Cameroon, (2017 at now).

$\mathrm{He}$ is a part-time lecturer in the Department of Mechanical Engineering, at College of Technology, University of Buea, Cameroon His areas of specialization are instability problems in Francis turbine, material, and fluids mechanics. 